\title{
FORMAÇÃO HUMANÍSTICA NOS CURSOS DE ODONTOLOGIA
}

\section{HUMANISTIC EDUCATION IN DENTISTRY COURSES}

\author{
Ana Cristina Kovalik ${ }^{1}$, Alessandra de Souza Martins ${ }^{2}$, \\ Wagner Izumi Sawada Germiniani ${ }^{3}$, Leide Mara Schmidt ${ }^{4}$ \\ ${ }^{1}$ Mestranda em Odontologia, Universidade Estadual de Ponta Grossa (UEPG). \\ E-mail: ana_kovalik@hotmail.com \\ ${ }^{2}$ Mestranda em Odontologia, Universidade Estadual de Ponta Grossa (UEPG). \\ E-mail: alessandraphn@hotmail.com \\ ${ }^{3}$ Mestrando em Odontologia, Universidade Estadual de Ponta Grossa (UEPG). \\ E-mail: wagnergerminiani@gmail.com \\ ${ }^{4}$ Professora doutora do Programa de Pós-Graduação em Odontologia - Mestrado, \\ Universidade Estadual de Ponta Grossa (UEPG). E-mail: lmschmidt@uol.com.br
}

Recebido para publicação em: 17/03/2010

Aceito para publicação em: 14/05/2010

\section{RESUMO}

O objetivo deste estudo foi analisar a sincronia entre a teoria e a prática dos docentes e discentes em relação à política de humanização do atendimento em saúde proposto desde a criação do SUS. Com a elaboração da Lei de Diretrizes e Bases da Educação Nacional (LDB) em 1996, e as Diretrizes Curriculares Nacionais do curso de Odontologia, a partir de 2002 houve a intensificação desta proposta, pela adição ao currículo mínimo de disciplinas que priorizem a questão humanística do atendimento, por entender que a transição do perfil de profissional unicamente tecnicista só ocorrerá se houver mudanças na abordagem ao paciente desde a graduação onde o aluno inicia seu contato com os pacientes. Concluiu-se que as instituições de ensino superior em odontologia estão rompendo a hegemonia do tecnicismo, porém, estão ocorrendo falhas na prática cotidiana, por que alunos e professores não estão conseguindo associar o aspecto ético-humanístico às habilidades técnicas e motoras durante o relacionamento entre si e com os pacientes. A primeira mudança deve ocorrer em relação aos docentes.

Palavras-chave: educação em odontologia; humanização pedagógica; satisfação do paciente.

\begin{abstract}
The aim of this article was to analyze the synchrony between theory and practice of teachers and students concerning the humanizing policy in the proposal of
\end{abstract}


health care centers since the creation of SUS (Unified Health System). After the elaboration of the Basic Guidelines for National Education Law (LDB) in 1966, and the National Curricular Guidelines for Dentistry courses, both implemented in 2002 , there has been an increased concern for humanistic care even in the curriculum of dentistry courses. This was possible due to the understanding that the change in the professional profile based only on the use of techniques will only take place if changes occur in the approach given to the issue since undergraduate courses, when students start dealing with patients. It was concluded that the institutions of higher education in dentistry are moving away from the technicist view of education, although there have been flaws in the daily practice as there are students and teachers who cannot relate the ethical-humanist aspect to the technical abilities in their relationships with patients and among themselves. Therefore, it is suggested that the first change should start with the teachers.

Keywords: Dentistry Education. Pedagogical humanizing. Patient satisfaction.

Atualmente o ensino e a prática em Saúde ainda sofrem resquícios de um passado em que se preconizava o tecnicismo sem levar em consideração a visão humanística entre profissional, aluno e paciente (LIMA, SOUZA, 2010; JUNQUEIRA, 2009; LUCATO, RAMOS, 2006; FREITAS, KOVALESKI, BOING, 2005; COSTA et al., 2002). Porém, independentemente de a atividade profissional estar vinculada ao serviço público ou à iniciativa privada, sabemos que alcançar o sucesso do atendimento e do tratamento depende do interrelacionamento entre os sujeitos envolvidos nesse processo. Por isso, o objetivo deste estudo é analisar associação entre a prática e a teoria da incorporação da humanização nos cursos de Odontologia.

Essa questão tornou-se mais valorizada após o surgimento do Sistema Único de Saúde (SUS) em 1988, momento em que foi criada a Política Nacional de Humanização - Humaniza SUS. (MINISTÉRIO DA SAÚDE, 2004).

Em 1996, foi elaborada a Lei de Diretrizes e Bases da Educação Nacional (LDB), que propiciou alterações das estruturas curriculares a nível nacional, acrescentando-se disciplinas de Ciências Sociais ao currículo mínimo dos cursos de Ciências da Saúde, para incorporar a realidade social ao âmbito da universidade. (MALTAGLIATI, GOLDENBERG, 2007; PRADO, GARRAFA, 2006).
A partir de 2002, as Diretrizes Curriculares Nacionais (DCNs) do curso de Odontologia, fundamentaram o planejamento dos cursos de graduação. Uma de suas propostas determina o perfil do profissional a ser formado:

[...] perfil generalista, que compreenda os determinantes sociais, culturais, comportamentais, psicológicos, ecológicos, éticos e legais, nos níveis individual e coletivo do processo saúde-doença, que possua uma sólida formação técnico-científica e ético-humanística, que seja crítico e reflexivo, sendo capaz de trabalhar em equipes multiprofissionais e de dar respostas às necessidades sociais no âmbito da profissão. (DCNs, 2002)

Para tal objetivo é necessário que os alunos dos cursos de graduação "aprendam a aprender" de acordo com os quatro pilares da Educação que engloba aprender a ser, aprender a fazer, aprender a viver juntos e aprender a conhecer, (SCALIONI et al., 2008; PRADO; GARRAFA, 2006; NUTO et al.., 2006; FREITAS et al. 2005; MOYSÉS, 2003).

Entende-se que a humanização nos serviços de saúde bucal só ocorrerá com mudanças nas formas de ensino das universidades por serem fontes de conhecimento e de contato inicial com a profissão e com os pacientes. (LIMA; SOUZA, 2010). 
Em Odontologia, além do projeto políticopedagógico, a humanização é priorizada no Código de Ética Odontológica, abordado na disciplina de Deontologia. Lucato e Ramos, em 2006, fizeram uma análise desse código, observando que nada mais é do que um conjunto de regras empregadas para resguardar a ética e o benefício do homem, associando sabedoria, ciência e ética, ou seja: humanização. Também fica claro que a humanização e a bioética se mesclam em alguns momentos, principalmente porque são embasados pelos princípios prima face preconizados por Beauchamp e Childress (1994) que são: autonomia, beneficência, não maleficência e justiça. Esses princípios, porém, não consideram o universo cultural do indivíduo, o que é encarado como uma limitação. Para Pyrrho et al. (2009), o Código de Ética Odontológica não exerce função humanística porque privilegia o cirurgião dentista e não o paciente, que tem posição vulnerável.

Segundo Trentin (2010), humanizar é tornarse humano, adquirir novos hábitos mais apropriados sob o prisma da Ética e da Moral distanciando-se da ignorância, estupidez, desamor... É educar-se sendo mais benévolo, enfim, evoluir o "eu espírito". $\mathrm{Na}$ área da Saúde, inicialmente o emprego do termo humanização foi baseado nas necessidades fisiológicas e biológicas, porém, essas seriam insuficientes para atingir o ser humano em sua totalidade, incluindo-se, portanto, as necessidades psicológicas que abordam a expressão e o respeito, o afeto, a simpatia e o relacionamento entre os envolvidos nos cuidados à saúde. Atualmente o termo humanização tem sido empregado para designar diversos aspectos do cuidado e assistência à saúde como: políticas de saúde, tecnologia, hospitalização e a interação no relacionamento paciente/profissional ou professor/aluno/paciente em casos de busca por atendimento em instituições de ensino(ALMEIDA; CHAVES, 2009; LUCATO; RAMOS, 2006; MINISTÉRIO DA SAÚDE, 2004) onde a humanização também foi definida como "a capacidade de oferecer atendimento de qualidade, articulando os avanços tecnológicos com o bom relacionamento". Todos esses aspectos tornam complexo quantificar a humanização, pois ela envolve o universo social, cultural e político, ou seja, os valores são individuais, tornando os sujeitos indivíduos únicos e, por isso, essa relação pode ser chamada de subjetiva. (LIMA; SOUZA, 2010; VAITSMAN; ANDRADE, 2005).

A relação sujeito/sujeito é a questão central e a humanização entre ambos dependerá da qualidade da interação. Destaca-se que a humanização ocorre pela valorização do profissional pelo paciente, do paciente pelo profissional, e de toda equipe envolvida no atendimento. (LUCATO; RAMOS, 2006; MINISTÉRIO DA SAÚDE, 2004).

Voltando para a questão da humanização no Ensino Superior, o que se discute é se a incorporação da humanização nas disciplinas dos cursos está ocorrendo de forma demagógica ou se realmente há mudanças na prática do cotidiano no relacionamento professor/aluno/paciente. Apesar de as universidades indicarem o ponto de partida das mudanças sobre os futuros profissionais, por serem fontes do conhecimento e de contato inicial com a profissão, terá efeito nulo se não houver reflexão e atitudes referenciais baseadas na Ética e na Moral por parte dos docentes, ou seja, não adianta o ensino ser inconsistente. (LIMA; SOUZA, 2010; ALMEIDA; CHAVES, 2009; FREITAS; PUPLAKSIS; RAMOS, 2007; KOVALESKI; BOING, 2005; CAMPOS, 2005; MOYSÉS, 2003). Somente após graduar futuros profissionais com uma formação realmente humanística é que será possível vivenciar a humanização nas relações sociais em Saúde fora das instituições. Segundo Benevides e Passos (2005, página 391) também deve haver a

[...] construção de uma política pública de práticas concretas no cotidiano dos serviços de saúde que tenha conexão com as forças do coletivo, com os movimentos sociais. Neste sentido a Política de Humanização só se efetiva uma vez que consiga sintonizar o que fazer com o como fazer, o conceito com a prática, o conhecimento com a construção da realidade.

Reafirma-se, portanto, a necessidade de um ensino efetivo sobre conceitos e práticas ético-humanistas, pois serão esses profissionais que terão a visão de como chegar a essa política pública humanista ideal. 
Outra face a ser discutida se refere às disciplinas que abordam o tema proposto. Todas as disciplinas podem e deveriam incorporar conceitos humanísticos em seus conteúdos teóricos e práticos, uma vez que a humanização está relacionada a princípios éticos e morais e aos direitos e deveres do profissional e do paciente. Porém, nem mesmo em disciplinas como Bioética e Deontologia o tema é exposto de maneira clara, crítica e conscientizadora. Em profissões como a Medicina e a Odontologia encontramos problemas que não são abordados nos códigos deontológicos, sendo inadequado ter apenas essa disciplina como referencial numa reflexão sobre conflito moral no exercício da profissão. A Bioética é a resposta para facilitarmos a integração das disciplinas acadêmicas e o reconhecimento do paciente como um ser biopsicossocial. (PUPLAKSIS; RAMOS, 2007).

Todos os aspectos acima relatados estão fundamentados em estudos realizados em instituições públicas e privadas de Ensino Superior de diversos estados brasileiros, como Santa Catarina, São Paulo, Rio de Janeiro, Brasília, Bahia, Rio Grande do Norte e Espírito Santo, acerca da percepção dos alunos, professores e usuários sobre o atendimento odontológico. Os temas analisados foram a Ética e a Moral e, dentre esses, a humanização, observando-se que: a comunicação é desqualificada, porque há pouca capacitação para um relacionamento dialogado; os alunos ainda têm uma visão de "troca de favores" em relação ao paciente usuário dos dispensários odontológicos, na qual o aluno precisa ser avaliado e o paciente precisa curar sua doença, desprezando o processo de comunicação e interação; o ambiente de formação não permite a compreensão do paciente como ser biopsicossocial e limita sua a autonomia, sendo predominante uma relação paternalista; o autoritarismo presente na relação professor/aluno e a baixa autoestima provocada pelo processo de ensino-aprendizagem são repetidos no relacionamento aluno/paciente, pois o professor é o modelo de conduta em que o aluno se espelha; para alguns alunos, o conhecimento sobre o relacionamento profissional/paciente não inclui aulas teóricas oferecidas na graduação, ocorrendo através do convívio informal com os colegas e docentes. Para outros, esse tipo de conhecimento teórico é muito importante e necessário, sendo que bioética e humanização possuem íntima correlação; o nível de desenvolvimento moral dos formandos encontra-se aquém do desejado para um profissional o que interfere nas relações éticas do cotidiano, trazendo consequências danosas para os pacientes e para sociedade; além ainda ocorre a valorização dos conhecimentos técnicos, científicos e de habilidades manuais, e a desvalorização da relação interpessoal (professor/aluno) no mesmo nível antropológico, como proposto pela Bioética Personalista. Nos projetos pedagógicos dos cursos de graduação na área da saúde, principlamente em Odontologia é explícita a intenção de formar profissionais com referenciais ético-humanísticos consistentes e, do mesmo modo, alunos, professores e usuários têm a percepção de que essa dimensão vem sendo trabalhada nos mesmos. Entretanto, a experiência com a realidade dos atendimentos demonstra que a prática é carente de reflexões e mudanças. (MATOS, 2010; LIMA; SOUZA, 2010; PUPLAKSIS; RAMOS, 2007; CAVACA; GOMES, 2007; NUTO et al., 2006; PRADO; GARRAFA, 2006; FREITAS; KOVALESKI; BOING, 2005;)

\section{Considerações finais}

Conclui-se que as instituições de Ensino Superior em Odontologia estão rompendo a hegemonia do tecnicismo, porém, há falhas na prática cotidiana, por que alunos e professores não estão conseguindo associar o aspecto ético-humanístico às habilidades técnicas e motoras durante o relacionamento entre ambos e os pacientes. A primeira mudança deve ocorrer em relação aos docentes.

\section{REFERÊNCIAS}

ALMEIDA, D. V.; CHAVES, E. C. O ensino da humanização nos currículos de graduação em enfermagem. Einstein, v.7, n.3, p.271-278, 2009.

BENEVIDES, R.; PASSOS, E. Humanização na saúde: um novo modismo? Interface - Comunic, Saúde, Educ, v.9, n.17, p.389-394, mar/ago. 2005. Doi: 10.1590/S141432832005000200014 . 
BRASIL. Ministério da Saúde. Núcleo Técnico da Política Nacional de Humanização. Documento base para trabalhadores e gestores do SUS: humaniza SUS. Brasília, 2009. Disponível em: <www.saude.gov.br/humanizasus>.

CAMPOS, G. W. S. Humanização na saúde: um projeto em defesa da vida? Interface - Comunic, Saúde, Educ., v.9, n.17, p.398-400, mar/ago. 2005.

CARVALHO, A. C. P. Reforma curricular da Odontologia. In: BOTAZZO, C.; OLIVEIRA, M. A. de (Orgs.). Atenção básica no Sistema Único de Saúde: abordagem interdisciplinar para os serviços de saúde bucal. São Paulo: Instituto de Saúde 2008. p.195-202.

COSTA, A. M. D. D., et al. Contribuição do perfil do aluno de graduação em odontologia para a redefinição dos recursos usados pelo professor no processo ensino-aprendizagem. Rev. Fac. Odontol. Lins, v.4, p.30-34, 2002.

DIRETRIZES Curriculares Nacionais do Curso de Odontologia. Disponível em: <www.mec.gov.br>. Acesso em: 13 jul. 2010.

FREITAS, S. F. T.; KOVALESKI, D. F.; BOING, A. F. Desenvolvimento moral em formandos de um curso de odontologia: uma avaliação construtivista. Ciência \& Saúde Coletiva, v.10, n.2, p.453-462, 2005

JUNQUEIRA, C. R. A atenção à pessoa humana - paciente e aluno - no âmbito da formação em odontologia: o papel do docente, da reestruturação curricular e da bioética, Faculdade de Odontologia do Estado de São Paulo, 2009. 200f. Tese (Doutorado em Odontologia Social). Faculdade de Odontologia da Universidade de São Paulo, São Paulo, 2009.

LIMA, E. N. A., SOUZA, E. C. F. Percepção sobre a ética e humanização na formação odontológica. RGO - Rev Gaúcha Odontol., Porto Alegre, 2010 abr./jun. v. 58, n. 2, p. 231-238

LUCATO, M. C.; RAMOS, D. L. P. A humanização das relações assistenciais no Código de Ética Odontológica. O Mundo da Saúde, v.30, n.3, p.417-424, 2006.

MALTAGLIATI, L. A.; GOLDENBERG, P. Reforma curricular e pesquisa na graduação em odontologia: uma história em construção. História, Ciências, Saúde - Manguinhos, Rio de Janeiro. 2007 v.14, n.4, p.1329-1340, out.-dez.

MATOS, M. S. Percepção de alunos, professores e usuários acerca da dimensão ética na formação de graduandos em Odontologia. 2010. Disponível em: <www.abrasco.org.br>. Acesso em: 18 jul. 2010.

MOYSÉS, S. J. A humanização da educação em odontologia: conhecimento e educação em saúde. Pro-posições/UNICAMP, v.14, n.1, p.87-106, 2003.

NUTO, S. A. S., et al. O processo de ensino-aprendizagem e suas consequências na relação professor-aluno-paciente. Ciência \& Saúde Coletiva, v.11, n.1, p.89-96, 2006.
PRADO, M. M.; GARRAFA, V. A Bioética na formação em odontologia: importância para uma prática consciente e crítica. Comun Ciênc Saúde. V.17, n.4, p.263-274, 2006.

PYRRHO, M.; PRADO, M. M.; CORDÓN, J.; GARRAFA, V. Análise bioética do Código de Ética Odontológica brasileiro. Ciência \& Saúde Coletiva, v.14, n.5, p.1911-1918, 2009.

SCALIONI, F. A. R.; ALVES, R. T.; DE MATOS, C. L. B.; RIBEIRO, R. A. Humanização na odontologia: a experiência da disciplina Odontopediatria II do Curso de Graduação em Odntologia da UFRJ. Pesq Bras Odontoped Clin Integr, João Pessoa, maio/ago, v.8, n.2, p.185-190, 2008.

TRENTIN, L. R. A. Humanização: o futuro da humanidade. Disponível em: $<$ http://www.meuartigo.brasilescola $>$. Acesso em: 13 jul. 2010.

VAITSMAN, J.; ANDRADE, G. R. B. Satisfação e responsividade: formas de medir a qualidade e a humanização da assistência à saúde. Ciência \& Saúde Coletiva, v.10, n.3 p.599-613, 2005. 